\title{
Proveniência de sedimentos da Bacia de Curitiba por estudos de minerais pesados
}

\author{
Denise Alessandra Monteiro Machado ${ }^{1 *}$, Luiz Alberto Fernandes ${ }^{2}$, Ana Maria Góes ${ }^{3}$, Maria José $^{2}$ \\ de Mesquita ${ }^{4}$ Fabio Macedo de Lima ${ }^{5}$
}

\begin{abstract}
Resumo A Bacia de Curitiba situa-se na porção Centro-sul do primeiro planalto paranaense. Inclui a cidade homônima e parte dos municípios da região metropolitana. É uma bacia neogênica alongada na direção ENE, que pertence ao Sistema de Riftes Cenozoicos do Sudeste do Brasil. Seu preenchimento sedimentar preservado estendese por $3.000 \mathrm{~km}^{2}$ e compreende lamas, areias arcosianas e cascalhos da Formação Guabirotuba. Dentre as bacias que integram o Sistema de Riftes Cenozoicos do Sudeste do Brasil, a Bacia de Curitiba é a menos estudada em detalhes. Até o presente momento, não foram divulgadas pesquisas de tal assembleia acessória. Foram analisados minerais pesados transparentes, não micáceos e não magnéticos, de fração granulométrica 3 - $4 \varphi(0,125-0,062 \mathrm{~mm})$, separados com uso de bromofórmio $\left(\mathrm{d}=2,89 \mathrm{~g} / \mathrm{cm}^{3}\right)$ e ímã de mão. A determinação foi feita com montagens permanentes de grãos, com bálsamo do Canadá $(\mathrm{n}=1,53)$, analisadas em microscópio petrográfico. $\mathrm{Na}$ assembleia mineralógica encontrada predominam grãos de zircão, além de epídoto, turmalina, cianita, rutilo e traços de sillimanita e granada. $\mathrm{O}$ zircão ocorre como grãos euédricos a subédricos incolores a subordinadamente róseos e metamícticos. $O$ estudo de minerais pesados na Bacia de Curitiba sugere que, em direção ao centro da bacia, as quantidades de zircão tendem a diminuir, enquanto as quantidades de epídoto aumentam. Foram caracterizadas duas associações mineralógicas: a primeira, denominada Alto Zircão, possui quantidades de zircão entre 51 a 97\%; a segunda foi denominada Alto Epídoto e tem quantidade máxima relativa de epídoto entre 31 a 53\%. Essas diferenças nos valores de zircão e epídoto permitem inferir a possibilidade de mais de uma área-fonte para estes sedimentos. As principais tendências de paleocorrentes indicaram como potenciais rochas-fonte os granitos da Província Graciosa e os metamorfitos do Complexo Atuba. Ainda, não se pode descartar a possibilidade de segregação hidráulica. O zircão, por ser mais denso, tem tendência de não avançar tanto no transporte da bacia adentro quanto o epídoto que apresenta densidade menor. Conclui-se, portanto, que a proporção relativa entre estes dois minerais seria um bom traçador da dinâmica de transporte sedimentar na bacia.
\end{abstract}

Palavras-chave: Bacia de Curitiba; minerais pesados; cenozoico.

\begin{abstract}
Sediment provenance of the Curitiba basin by study of heavy minerals. Curitiba Basin is located in the South-central portion of the first plateau of Paraná. It includes the city of the same name and some towns of the metropolitan region. It is a neogean basin elongated towards ENE direction, which belongs to the Cenozoic Rift System in Southeast Brazil. Its maintained sedimentary fill extends over 3,000 km2 and includes sludge, arkosic sands, and gravels of Guabirotuba Formation. Among the basins that are part of the Cenozoic Rift System of Southeast Brazil, Curitiba Basin is the least studied in details. Until the present moment, researches on this accessory assembly were not disclosed. We have analyzed transparent, nonmicaceous and nonmagnetic heavy minerals, with fraction of particle size from $3-4 \varphi(0.125-0.062 \mathrm{~mm})$, which were separated using bromoform $\left(\mathrm{d}=2.89 \mathrm{~g} / \mathrm{cm}^{3}\right)$ and handheld magnet. The determination was done with permanent assemblies of grains and Canada balsam $(\mathrm{n}=1.53)$, analyzed in a petrographic microscope. In the mineralogical assembly, zircon grains, epidote, tourmaline, kyanite, rutile, and traces of sillimanite and garnet were predominantly found. Zircon occurs as euhedral to sub-euhedral grains, colorless to subordinate pink and metamict. The study of heavy minerals in Curitiba Basin suggests that towards the center of the basin, zircon quantities tend to decrease while amounts of epidote increase. Two mineralogical associations were characterized: the first, called High Zircon, has zircon quantities between 51 to 97\%; the second one was called High Epidote and has relative epidote amounts between 31 to 53\%. Such differences in zircon and epidote values allow to infer the possibility of having more than one source area for these sediments. The main paleocurrents trends indicated the granites of Graciosa Province and metamorphic rocks of the Atuba Complex as potential source rocks. Moreover, one cannot rule out the possibility of hydraulic segregation. Since zircon is denser, it tends not to move so much the basin transport as the epidote, which presents the lowest density. Therefore, it was concluded that the relative proportion between these two minerals would be a good tracer of the dynamics of sediment transportation in the basin.
\end{abstract}

Keywords: foraminifera; Curitiba Basin; heavy minerals; cenozoic.

${ }^{1}$ Universidade Federal do Paraná - UFPR, Curitiba (PR), Brasil. E-mail: denise.amm@gmail.com

${ }^{2}$ Departamento de Geologia, Universidade Federal do Paraná - UFPR, Curitiba (PR), Brasil. E-mail: lufernades@ufpr.br

${ }^{3}$ Instituto de Geociências, Universidade de São Paulo - USP, São Paulo (SP), Brasil. E-mail: goes@igc.usp.br

${ }^{4}$ Departamento de Geologia, Universidade Federal do Paraná - UFPR, Curitiba (PR), Brasil. E-mail: mj_mesquita@ufpr.br

${ }^{5}$ Universidade Federal do Paraná - UFPR, Curitiba (PR), Brasil. E-mail: receba@gmail.com

*Autor correspondente 
Introdução Os minerais pesados são acessórios das rochas sedimentares, que, apesar de sua baixa concentração, são importantes indicadores dos processos sedimentares e podem ser utilizados para correlações estratigráficas, estudos de proveniência e dispersão sedimentar (Krumbein \& Pettijohn 1938, Krumbein \& Sloss 1956, Morton \& Hallsworth 1994, Tomazelli 1978, Mezzadri \& Saccani 1989, Calliari et al. 1990). Contudo, a análise de sua concentração e distribuição é insuficiente para resolução destas importantes questões, e deve ser integrada com outros dados analíticos. Apesar da reconhecida importância e de sua identificação não exigir técnicas de grande sofisticação, até o presente, não existem publicações sobre minerais pesados da Formação Guabirotuba, principal unidade sedimentar da Bacia de Curitiba. Os resultados dos estudos de proveniência da Formação Guabirotuba são muito importantes para as reconstituições paleogeográficas destes depósitos. Este estudo, associado a informações sobre ambientes deposicionais e sobre evolução sedimentar, visa a contribuir com novos resultados ao conhecimento da evolução dos depósitos clásticos cenozoicos do Sudeste/Sul do Brasil. Outro aspecto que merece atenção é o fato de que a cidade de Curitiba desenvolveu-se principalmente sobre a bacia sedimentar homônima. A melhor compreensão da distribuição das unidades sedimentares é fundamental para o correto planejamento do uso e ocupação do território, assim como da potencialidade e distribuição de águas subterrâneas e outros recursos naturais da região, tais como depósitos de argila.

A despeito do fácil acesso, a ausência de boas exposições tem dificultado o entendimento geológico desta importante bacia sedimentar.

Os resultados ora apresentados são de uma pesquisa de caracterização da composição mineralógica acessória dos sedimentos arenosos da Formação Guabirotuba (Machado 2009), principalmente de sua borda Leste, na qual foram registradas suas melhores exposições.

\section{CONTEXTO GEOLÓGICO Desdobramentos} de processos tectônicos relacionados à abertura do Oceano Atlântico resultaram no desenvolvimento de bacias tafrogênicas (Almeida 1952, Melo et al. 1985, Riccomini et al. 2004) ao longo da vertente ocidental da Serra do Mar, que, posteriormente, Zalán \& Oliveira (2005) denominaram de Sistema de Riftes Cenozoicos do Sudeste do Brasil (SRCSB).
A Bacia de Curitiba possui atualmente forma alongada de direção NE - SW, com aproximadamente $3.000 \mathrm{~km}^{2}$ de área.

Os sedimentos da Formação Guabirotuba assentam-se discordantemente sobre rochas do Complexo Atuba, o qual é composto por orto e paragnaisses, com intercalações frequentes de anfibolitos, xistos magnesianos, mica e quartzitos (Siga Jr. et al. 1995). Esses conjuntos litológicos apresentam paragênese de grau metamórfico médio a alto, da fácies anfibolito (Salamuni et al. 1999). As rochas do Complexo Atuba são de idade proterozoica inferior, com idades $\mathrm{Rb}-\mathrm{Sr}$, distribuídas no intervalo de 2.200 a $1.800 \mathrm{Ma}$, e U-Pb em zircão próximas de $2.100 \mathrm{Ma}$ (Siga Jr. et al. 1995).

A Leste-sudeste, o embasamento exposto é constituído pelas rochas da Província Graciosa (Gualda e Vlach 2005), anteriormente denominada de Suíte Granítica Serra do Mar (Kaul 1984). Nesta, encontram-se algumas das mais expressivas ocorrências de granitos e sienitos alcalinos com associação aluminosa do Sul do Brasil. Cinco corpos independentes são reconhecidos (Gualda e Vlach 2005): Marumbi, Anhangava, Capivari, Órgãos e Farinha Seca. Nestas, são reconhecidas duas associações petrográficas: a alcalina, que inclui álcali-feldspato granitos e sienitos hipersolvus, peralcalinos a metaluminosos (Anhangava, Farinha Seca e Órgãos), e a aluminosa, composta por granitos subsolvus metaluminosos a marginalmente peraluminosos (Capivari, Órgãos, Anhangava e Marumbi). As idades relativas variam de 520 a $600 \mathrm{Ma}, \mathrm{Rb}-\mathrm{Sr}$ em rocha total (Siga Jr. et al. 1995, Kaul \& Cordani 2000).

A Norte e a Noroeste, o embasamento da Bacia de Curitiba é constituído por rochas da Formação Capiru, do Grupo Açungui. O Grupo Açungui é composto pelas formações Votuverava, Capiru e Itaiacoca. Porém, na área de estudo, ocorre apenas a Formação Capiru, formada por rochas de baixo grau metamórfico, fácies xisto verde e que compreende metacalcários, filitos, metassiltitos e quartzitos, todos de idade proterozoica (Fiori \& Gaspar 1993), como observado no Quadro 1 e na Fig. 1.

Formação Guabirotuba Bigarella \& Salamuni (1962) dividiram os sedimentos da Bacia de Curitiba em: depósitos de várzea e mais antigos, considerados pleistocênicos por estes autores. Foi proposta a denominação "Formação Guabirotuba" para estes últimos, por apresentarem as melhores exposições no bairro homônimo. 


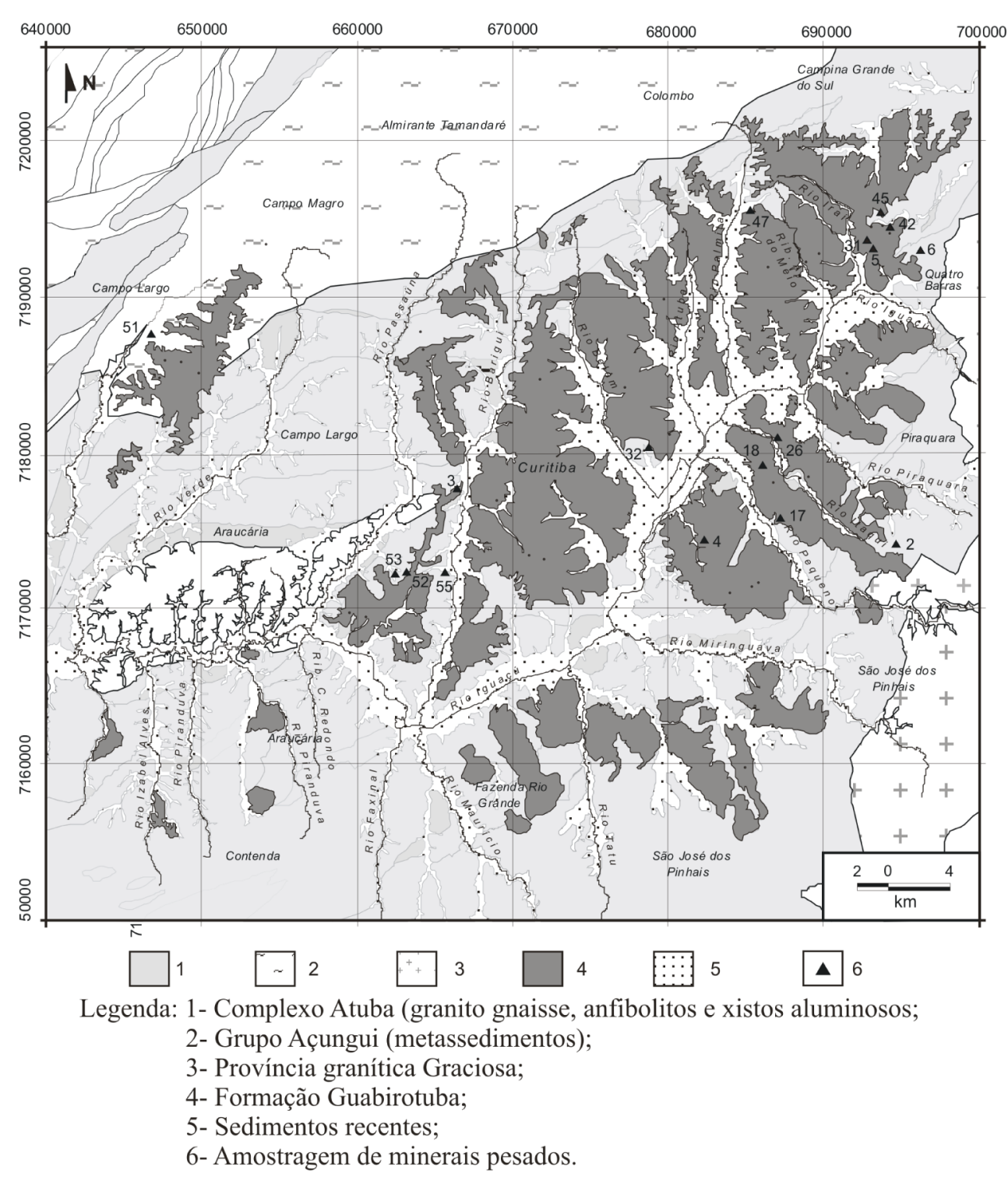

Figura 1 - Bacia de Curitiba e embasamento adjacente, locais de estudo e amostragem. Modificado de Salamuni et al. (1999).

Nos estudos de Bigarella \& Salamuni (1962) e Becker (1982), sugeriu-se que, quanto ao preenchimento, a Bacia de Curitiba poderia ser dividida em três unidades distintas com base em critérios geomorfológicos: Formação Guabirotuba, unidade inferior constituída por depósitos gerados durante a elaboração da superfície do Alto Iguaçu; Formação Tinguis, unidade superior separada da anterior por discordância erosiva, sendo composta por sedimentos retrabalhados da Formação Guabirotuba e sedimentos mais recentes dos depósitos das planícies de inundação dos rios atuais que formam as várzeas holocênicas. Coimbra et al. (1995) propuseram a individualização de parte da Formação Guabirotuba, designando-se a nova unidade como Formação Piraquara. Sua origem estaria relacionada a um período de pouca ou nenhuma tectônica, associada ao clima úmido, durante o final do Oligoceno e início do Mioceno.

Lima (2010), baseando-se em análise faciológica, discutiu com maiores detalhes o contexto deposicional da Formação Guabirotuba e identificou seis associações de fácies sedimentares $(\mathrm{A}, \mathrm{B}, \mathrm{C}$, D, E e F). Assim como os autores anteriores, Lima (2010) atribuiu o contexto deposicional da Formação Guabirotuba a ambientes fluviais.

Conforme a proposta deste autor pode-se caracterizar os depósitos da Formação Guabirotuba, da borda Oriental em direção a Oeste, em:

- Associação A - depósitos proximais dos fluxos de detritos retrabalhados por rios de canais entrelaçados. 


\begin{tabular}{|c|c|c|c|c|c|}
\hline Eon & Era & Período & Época & $\begin{array}{l}\text { Unidade } \\
\text { litoestratigráfica }\end{array}$ & Constituição \\
\hline \multirow{3}{*}{ Fanerozoico } & \multirow{2}{*}{ Cenozoico } & Quaternário & Holoceno & $\begin{array}{l}\text { Depósitos coluvionares/ } \\
\text { aluvionares }\end{array}$ & Areias mal selecionadas, argilosas \\
\hline & & Neógeno & $\begin{array}{l}\text { Plioceno } \\
\text { Mioceno }\end{array}$ & Formação Guabirotuba & $\begin{array}{l}\text { Argilas, areias arcosianas, cascalhos, } \\
\text { calcretes }\end{array}$ \\
\hline & Paleozóico & Cambriano & & $\begin{array}{l}\text { Província Graciosa } \\
\text { (Granitos Capivari, } \\
\text { Órgãos, Farinha Seca, } \\
\text { Marumbi e Anhangava) }\end{array}$ & $\begin{array}{l}\text { Granitos e sienitos alcalinos } \\
\text { (anfibólio de K e Na, feldspatos, } \\
\text { biotita, titanita, zircão, allanita, } \\
\text { quartzo, fluorita, chevkinita- } \\
\text { perrierita, ilmenita e magnetita }\end{array}$ \\
\hline \multirow[b]{2}{*}{ Proterozoico } & Neoproterozoico & & & $\begin{array}{l}\text { Grupo Açungui } \\
\text { (formações Capiru, } \\
\text { Votuverava e Itaiacoca) }\end{array}$ & $\begin{array}{l}\text { Metacalcários, metapelitos, } \\
\text { quartzitos, metaconglomerados, } \\
\text { metabásicas, (calcita, dolomita, } \\
\text { quartzo, clorita, mica branca, biotita) }\end{array}$ \\
\hline & Paleoproterozoico & & & Complexo Atuba & $\begin{array}{l}\text { Granito-gnaisses, anfibolitos e } \\
\text { metaultrabasitos, xistos aluminosos, } \\
\text { paragnaisses e quartzitos } \\
\text { (plagioclásio, K-feldspato, quartzo, } \\
\text { hornblenda, piroxênio, granada, } \\
\text { biotita e clorita, epidoto, zoizita, } \\
\text { allanita, titanita, zircão, apatita }\end{array}$ \\
\hline
\end{tabular}

Fonte: Fiori (1990), Siga Jr. et al. (1995), Salamuni et al. (1999), Gualda \& Vlach (2005).

Quadro 1 - Estratigrafia da Bacia de Curitiba e embasamento adjacente.

- $\quad$ Associação B - feições acanaladas arenosas escavadas em lamas, também relacionadas a rios de canais entrelaçados de menor energia.

- $\quad$ Associação $\mathrm{C}$ - feições acanaladas amplas formadas por estratos lenticulares e tabulares menores, sugerindo ambiente com rios de menor energia, entrelaçados em intervalos de menor vazão.

- $\quad$ Associação D - corresponde à zona distal dos leques aluviais da Formação Guabirotuba, há ocorrência de calcretes nodulares e tabulares (Cunha 2011), que são depósitos de inundações laminares intercalados com depósitos dos fluxos de detritos distais.

- $\quad$ Associação E - constitui depósitos de rios entrelaçados por sistemas de leques aluviais da borda Noroeste. O autor verificou, ainda, com base na hierarquia das superfícies erosivas e nos rumos médios de paleocorrentes, que a Associação E corresponderia à Formação Tinguis de Becker (1982). A Associação E intercala-se com as associações $\mathrm{C}$ e D, portanto, é contemporânea às demais.
- $\quad$ Associação F - Lima (2010), por não encontrar relações estratigráficas suficientes para adotar a Formação Piraquara de Coimbra et al. (1995), relacionou-a à Associação $\mathrm{F}$, interpretada como depósitos de rios sinuosos a meandrantes, porém sujeitos a intervalos de maior energia (Fig. 2).

Segundo Lima (2010), tais associações correspondem a ambientes fluviais transicionais da zona proximal à distal de sistemas leques aluviais marginais, formados ao longo da Província Graciosa.

MÉTODOS As melhores exposições da Formação Guabirotuba estão na borda Leste da bacia. Por tal razão, ali concentraram-se os locais de caracterização sedimentar e amostragem para a pesquisa. Coletaram-se sedimentos arenosos com granulação semelhante para evitar efeitos de segregação hidráulica na assembleia de minerais pesados. Foram amostrados 17 pontos, apresentados na Fig. 1 .

Os sedimentos foram elutriados para a separação da fração síltico-argilosa. Após a secagem, as areias foram peneiradas para separação da fração 0,125 - 0,062 mm, selecionada para análise de 


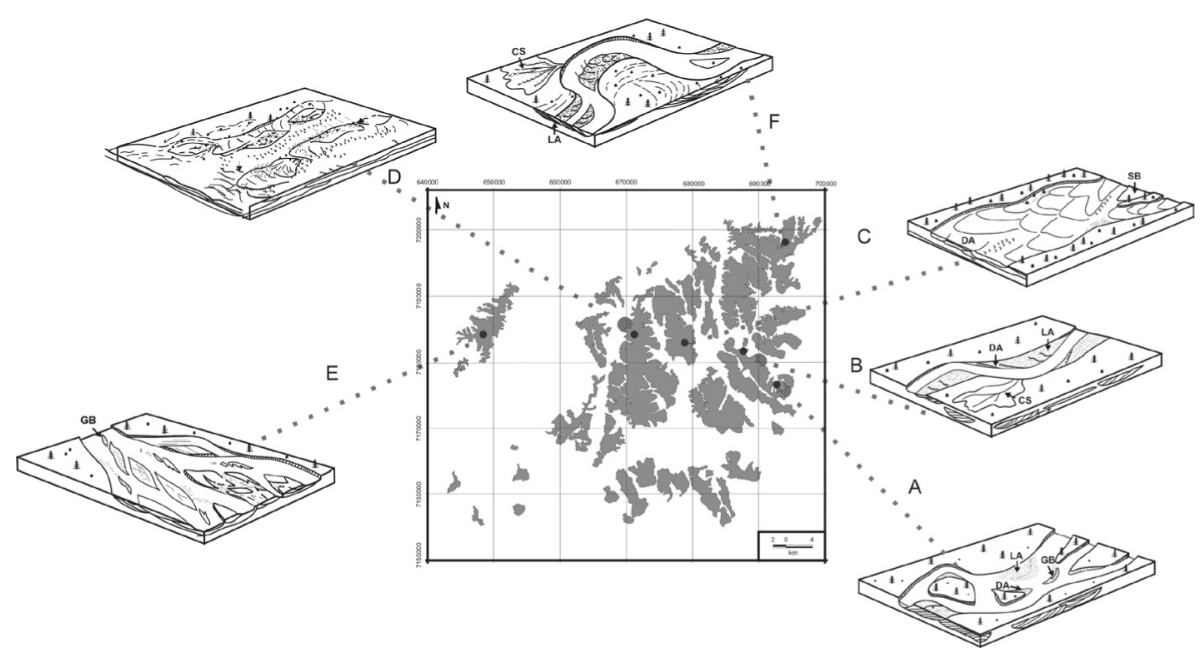

Figura 2 - Associações de fácies na Bacia de Curitiba. Modificado de Earth Science Review - Miall (1985) e Lima (2010).

minerais pesados. Este intervalo foi escolhido por apresentar maior volume de minerais pesados e ser facilmente identificável ao microscópio petrográfico.

A separação de minerais pesados foi realizada por imersão em bromofórmio e, posteriormente, os minerais magnéticos foram retirados com ímã de mão. Os concentrados de pesados foram montados em lâminas de vidro com bálsamo do Canadá natural. A identificação dos minerais pesados transparentes não micáceos foi feita com microscópio petrográfico, com base em suas propriedades óticas e em algumas feições características, tais como: forma, cor, pleocroísmo, clivagem, inclusões e alteração, descritas na literatura (Mange \& Maurer 1992). A quantificação foi feita com base no método de contagem por linhas (Galehouse 1971), contando-se de 100 a 200 grãos por lâmina. A abundância relativa de cada mineral foi expressa em porcentagem em tabela, em que aqueles com porcentagem inferior a $1 \%$ foram considerados traços. Além disso, calculou-se a frequência média por meio da média aritmética das frequências individuais do mineral; da frequência de ocorrência (Coimbra 1976), que é obtida dividindo-se o número de amostras nas quais o mineral está presente pelo número de amostras; e, finalmente, a de classe, a partir de uma classificação de abundância, em que foi considerado superabundante o mineral com frequência superior a $50 \%$, abundante entre 10 a $50 \%$, comum entre 2 a $10 \%$ e raro maior que zero e menor que $2 \%$, conforme proposta de Coutinho \& Coimbra (1974).

Os rumos médios de paleocorrentes foram obtidos a partir das atitudes de planos de estratificação cruzada em estratos arenosos. Adicionalmente, utilizaram-se também atitudes de clastos de formas discoide e lamelar, imbricados, dispersos em matriz de areias cascalhosas e cascalhos.

\section{ANÁLISE DE MINERAIS PESADOS}

A avaliação dos minerais pesados da Formação Guabirotuba revelou que as concentrações desses minerais variaram de 0,24 a $2,61 \%$, de forma que a média das concentrações é de $0,92 \%$ (Tab. 1). Tais valores estão dentro dos padrões esperados para mineralogia acessória de rochas sedimentares.

A análise dos minerais pesados transparentes não micáceos presentes nos sedimentos da Formação Guabirotuba indicou assembleia com baixa diversidade mineralógica (Tab. 2). Os minerais com maior frequência de ocorrência são: zircão, epídoto, turmalina e cianita. Dentre estes, os mais abundantes são zircão e epídoto, classificados, respectivamente, por frequência de classes, em superabundante e abundante (Tab. 3). A somatória das frequências médias destes minerais perfaz mais de $90 \%$ do total de minerais pesados presentes. Mais raramente, em quantidades traço, ocorrem cianita, sillimanita, granada e hornblenda.

\section{Feições gerais dos minerais encontrados}

Zircão Mineral superabundante com $100 \%$ de ocorrência nas amostras. Seus grãos medem em média de 0,125 a 0,070 mm. Apresentam-se, principalmente, como grãos prismáticos bipiramidados com extremidades subarredondadas a arredondadas. Secundariamente, ocorrem grãos anédricos arredondados a subangulosos, e grãos prismáticos com as pirâmides bem conservadas são mais raros. São, em geral, incolores a subordinadamente róseos, neste caso com fraco pleocroísmo. Em geral, os 
grãos são límpidos com pequenas inclusões e, raramente, metamícticos.

Epídoto Mineral abundante com 100\% de ocorrência. Ocorre nas variedades epídoto e zoisita, destes o mais abundante e mais frequente é o epídoto. Os grãos, de ambos, medem em média $0,050 \mathrm{~mm}$, com formas dominantemente anédricas subarredondadas e, muito raramente, euédricas. A variedade epídoto se apresenta verde brilhante, enquanto a zoisita ocorre como grãos incolores. Grãos límpidos são raros e os mais comuns apresentam textura superficial rugosa e aspecto turvo.

Tabela 1 - Porcentagem em massa de minerais pesados em relação à massa total

\begin{tabular}{cc}
\hline Amostra & \% de minerais pesados \\
\hline BC 02 & 0,94 \\
\hline BC 03 & 1,23 \\
\hline BC 04 & 1,53 \\
\hline BC 05 & 1,73 \\
\hline BC 06 & 0,87 \\
\hline BC 17 18 & 0,26 \\
\hline BC 18 26 & 0,80 \\
\hline BC 31 & 0,24 \\
\hline BC 32 & 0,25 \\
\hline BC 42 & 0,83 \\
\hline BC 45 & 1,14 \\
\hline BC 47 & 1,10 \\
\hline BC 51 5 51 \\
\hline BC 52 & $\mathrm{N}$ \\
\hline BC 53 & 0,56 \\
\hline BC 55 & $\mathrm{N}$ \\
\hline Média & 1,57 \\
\hline
\end{tabular}

$\mathrm{N}=$ não foi possível obter as porcentagens.
Turmalina Mineral comum com $94 \%$ de ocorrência. $\mathrm{O}$ valor médio encontrado é de $4,4 \%$, embora existam valores altos de 17 a $20 \%$ em locais isolados. Os grãos medem em média $0,050 \mathrm{~mm}$ e são anédricos subarredondados a bem arredondados, raramente prismáticos. Em relação à cor, predomina-se verde oliva a castanho-escuro, e, mais raramente, azul claro a azul-escuro.

Cianita Mineral comum com $70 \%$ de ocorrência. O tamanho médio dos grãos é de 0,040 a $0,060 \mathrm{~mm}$. O hábito é anédrico subanguloso a anguloso, com frequentes inclusões carbonosas. Secundariamente, foram encontrados grãos prismáticos, em geral, mais límpidos do que os anédricos.

Rutilo É um mineral raro com $70 \%$ de ocorrência. O tamanho médio dos grãos é de $0,040 \mathrm{~mm}$. O hábito é anédrico preferencialmente anguloso a subarredondado, secundariamente foi encontrado hábito prismático com geminação cotovelo. Os grãos são marrons e raramente amarelos.

Outros minerais Granada e sillimanita são minerais raros na assembleia estudada, ambos apresentam $36 \%$ de frequência de ocorrência. Têm em média $0,030 \mathrm{~mm}$ e predominam grãos anédricos subangulosos a subarredondados.

DISCUSSÃO A análise da distribuição dos minerais pesados na Bacia de Curitiba revelou a supremacia de zircão e epídoto como os minerais mais

Tabela 2 - Frequência relativa dos minerais pesados transparentes não micáceos dos sedimentos arenosos da Formação Guabirotuba

\begin{tabular}{|c|c|c|c|c|c|c|c|c|}
\hline Amostras & $\mathrm{n}$ & Zircão & Epídoto & Turmalina & Rutilo & Cianita & Sillimanita & Granada \\
\hline $\mathrm{BC} 02$ & 200 & 87 & 12 & TR & 1 & 0 & 0 & 0 \\
\hline BC 03 & 200 & 53 & 43 & TR & TR & TR & 0 & 4 \\
\hline BC 04 & 200 & 80 & 14 & 3 & 2 & TR & 1 & 0 \\
\hline BC 05 & 174 & 93 & 6 & TR & 0 & 1 & 0 & 0 \\
\hline BC 06 & 200 & 97 & 3 & 0 & 0 & 0 & 0 & 0 \\
\hline BC 17 & 112 & 90 & 7 & 3 & TR & 0 & 0 & 0 \\
\hline BC 18 & 200 & 88 & 9 & 1 & 2 & 0 & 0 & 0 \\
\hline BC 26 & 200 & 45 & 54 & 1 & TR & TR & 0 & 0 \\
\hline BC 31 & 111 & 91 & 6 & 3 & 0 & 0 & TR & 0 \\
\hline BC 32 & 200 & 47 & 48 & 3 & 2 & TR & 0 & 0 \\
\hline BC 42 & 200 & 92 & 5 & 2 & TR & TR & 0 & 1 \\
\hline BC 45 & 200 & 89 & 8 & 3 & TR & TR & 0 & 0 \\
\hline BC 47 & 200 & 51 & 2 & 17 & 3 & 27 & TR & 0 \\
\hline BC 51 & 200 & 36 & 45 & 6 & 1 & 12 & TR & 0 \\
\hline BC 52 & 200 & 87 & 8 & 2 & & TR & 2 & 0 \\
\hline BC 53 & 127 & 86 & 7 & 3 & 0 & 4 & 0 & 0 \\
\hline BC 55 & 200 & 87 & 5 & 4 & & 3 & TR & 0 \\
\hline
\end{tabular}

*Convenções: $\mathrm{n}$ = número de grãos contados; $\mathrm{TR}=$ traço (frequência $<1 \%$ ). 
abundantes em todas as amostras. De acordo com as proporções relativas entre estes minerais, foram agrupadas duas associações (Quadro 2), denominadas de Alto Zircão e Alto Epídoto.

Os grãos de zircão, por oferecerem resistência a processos físicos e químicos naturais, são frequentes entre minerais detríticos resistatos na maioria dos depósitos sedimentares. Vale salientar que este mineral também resiste a transformações hidrotermais, metamórficas e até mesmo à fusão parcial. A baixa velocidade de difusão dos íons na estrutura cristalina do zircão favorece a preservação de sua composição química e isotópica, durante a maior parte dos processos geológicos. Desta forma, por exemplo, o zircão de rochas granitoides comumente exibe idades anteriores a de sua cristalização, por ser produto do protólito metamórfico ou proveniente de rochas encaixantes parcialmente assimiladas (Cherniak et al. 1997). Dos 17 locais amostrados, 13 apresentam domínio absoluto de zircão. A associação Alto Zircão apresenta quantidades relativas do mineral entre $80 \mathrm{e}$ $97 \%$, o que o torna um mineral superabundante. Tal associação encontra-se distribuída por praticamente toda a Bacia de Curitiba (Tab. 2 e Fig. 1). A quantidade de grãos euédricos a subédricos - cerca de $70 \%$ dos grãos - indica, possivelmente, que a maior parte dos grãos foi pouco transportada, supondo-se que grande parte deste mineral provém diretamente de rochas graníticas de fontes a Leste e Oeste, relacionadas à Província Graciosa ou ao Granito Guajuvira,

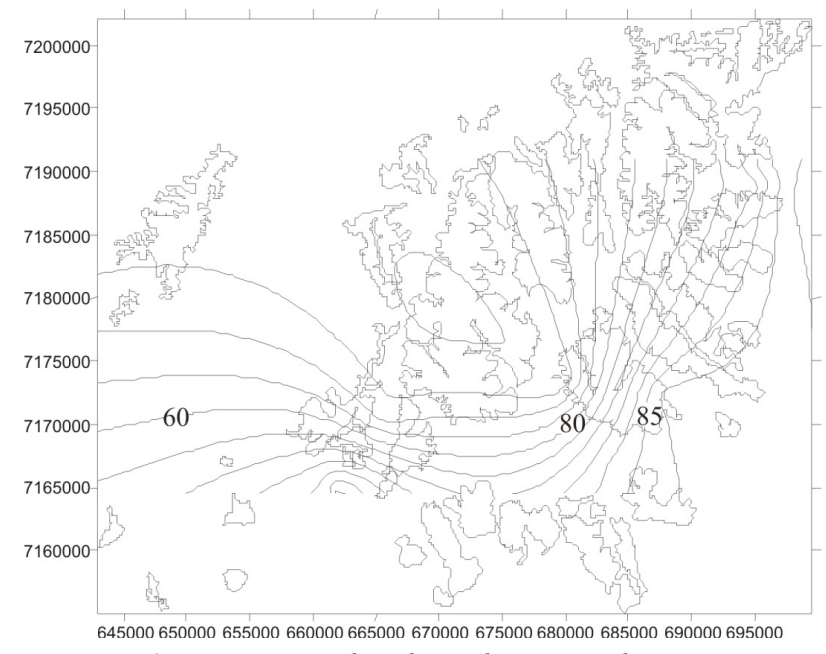

Figura 3 - Mapa de distribuição de zircão na Bacia de Curitiba.

respectivamente. Além disso, outra fonte potencial são os metamorfitos do Complexo Atuba (Fig. 1). A distribuição de isovalores de frequência de zircão (Fig. 3) e rumo médio de paleocorrentes (Fig. 4), com sentido preferencial de SE-NW (Lima 2010), corroboram tal interpretação.

Os minerais do grupo do epídoto são aluminossilicatos de cálcio hidratados, inerentes a uma grande variedade de paragêneses. Esses minerais são típicos produtos de metamorfismo regional de grau baixo a médio, de rochas básicas e cálcio-silicatadas. Também podem se formar em condições de metamorfismo de contato, nas fácies epídoto, ou metamorfismo de contato em rochas carbonatadas. Ainda, é possível se formar durante a cristalização

Tabela 3 - Frequências de ocorrência e de classes para os minerais pesados dos sedimentos arenosos da Formação Guabirotuba

\begin{tabular}{lccc}
\hline Mineral & Frequência média (\%) & Frequência de ocorrência (\%) & Frequência de classes (\%) \\
\hline Zircão & 76 & 100 & Superabundante \\
\hline Epídoto & 17 & 100 & Abundante \\
\hline Turmalina & 3 & 94 & Comum \\
\hline Cianita & 3 & 70 & Comum \\
\hline Rutilo & TR & 70 & Raro \\
\hline Sillimanita & TR & 30 & Raro \\
\hline Granada & TR & 6 & Raro \\
\hline
\end{tabular}

\begin{tabular}{|lcc|}
\hline \multicolumn{1}{|c}{$\begin{array}{c}\text { Associações de minerais pesados na } \\
\text { Bacia de Curitiba }\end{array}$} & $\begin{array}{c}\text { Associação } \\
\text { Alto Zircão }\end{array}$ & $\begin{array}{c}\text { Associação } \\
\text { Alto Epídoto }\end{array}$ \\
\hline Quantidades limites de zircão & Zircão (51 a 97\%) & Zircão (36 a 53\%) \\
\hline Quantidades limites de epídoto & Epídoto (2 a 14\%) & Epídoto (43 a 54\%) \\
\hline$* \mathrm{n}$ & 13 & 4 \\
\hline
\end{tabular}

*n = número de amostras por associação.

Quadro 2 - Associações principais de minerais pesados da Bacia de Curitiba, de acordo com suas quantidades relativas. 


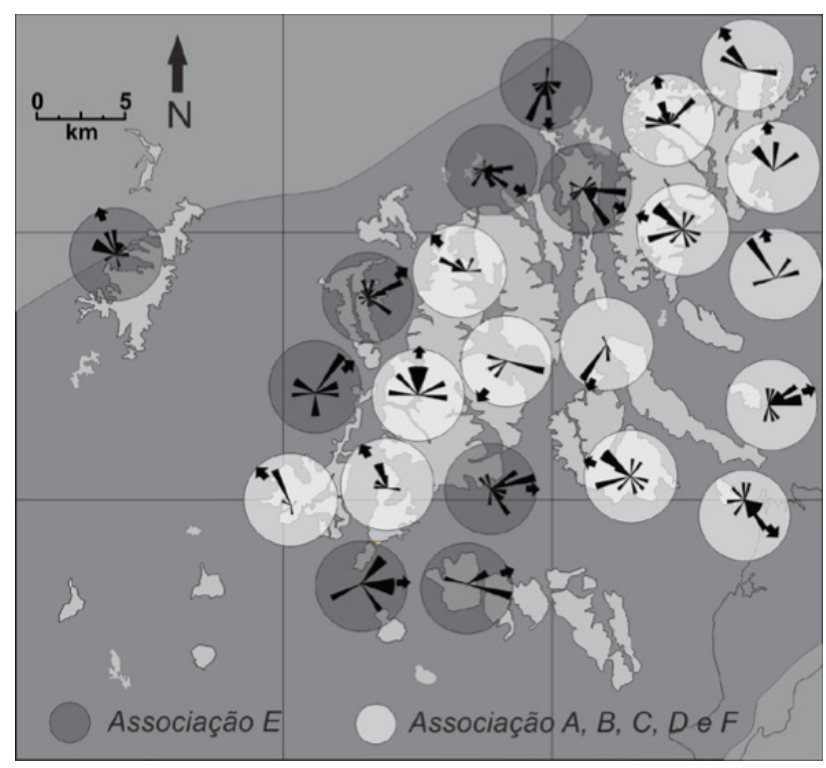

Figura 4-Paleocorrentes da Bacia de Curitiba.

das rochas ígneas ácidas. A zoisita ocorre em metabasitos. É possível uma solução sólida contínua entre estes minerais, e um exemplo disso são as rochas portadoras de ferro, em que há coexistência dos mesmos, em amplo espectro de condições. Porém, em condições de ausência de ferro, a zoisita possui entropia mais alta, sendo, portanto, típica do metamorfismo de pressão relativamente elevada ou temperatura elevada, enquanto o epídoto é mais comum em graus metamórficos baixos, tais como xistos verdes e anfibolitos (Deer et al. 2000). O epídoto é o mineral mais abundante da associação Alto Epídoto, com variação de 41 a $54 \%$, e ocorre em quatro locais, dos quais três estão quase alinhados $\mathrm{E} / \mathrm{W}$, aproximadamente no centro da Bacia de Curitiba. Admite-se que suas fontes podem estar relacionadas principalmente aos ortognaisses de fácies anfibolito (Siga Jr. et al. 1995) ou anfibolitos do Complexo Atuba, já que o rumo médio de paleocorrentes (Lima 2010) revelou tendência geral de fluxo para Noroeste (Fig. 2).

Esse par de minerais possivelmente provém das mesmas áreas a Leste ou Oeste ou de ambas. A questão é porque ora as concentrações estão enriquecidas de um ou de outro mineral. Existe um padrão de distribuição destes minerais, indicando que à medida que aumenta a frequência de epídoto, diminui a de zircão, considerando-os no mesmo intervalo estratigráfico. Entretanto, observa-se que existe uma grande correlação entre as associações faciológicas e as mineralógicas. O aumento de epídoto ocorre em direção às associações de fácies mais distais. Por exemplo, o local BC17 (Fig. 2) está situado na associação de fácies A (Lima 2010), proximal e tem quantidade relativa de zircão de $90 \%$ e de epídoto de apenas $7 \%$. Avançando ao centro da bacia, o local BC18, na associação de fácies $\mathrm{B}$, proximal intermediária, tem quantidades relativas de zircão e epídoto, respectivamente, de 88 e $9 \%$. Enquanto que o local BC32, que está na associação de fácies $\mathrm{C}$, intermediária, tem quantidade relativa de zircão de apenas $47 \%$ e o epídoto aumenta para $48 \%$.

Diante desses fatos, é possível refletir sobre a influência do processo de segregação hidráulica nesta diferenciação mineralógica. $\mathrm{O}$ zircão por ser mais denso $\left(4,6\right.$ a $\left.4,7 \mathrm{~g} / \mathrm{cm}^{3}\right)$ tem tendência a não avançar tanto no transporte quanto o epídoto, que apresenta densidade menor $(3,35$ a 3,49). A segregação hidráulica poderia, portanto, ser uma explicação para a diferença entre as associações Alto Zircão e Alto Epídoto. Ainda, o local 51, que também está incluído na associação Alto Epídoto, não forneceu até o momento informações que possam corroborar com os outros três locais de ocorrência desta associação. Esta associação faciológica precisa ser ainda melhor compreendida quanto à sua possível contemporaneidade em relação às demais associações identificadas na Formação Guabirotuba. Outro fato relevante é a grande diferença de estabilidade química e física destes dois minerais. De fato, o epídoto é mineral metaestável, enquanto o zircão é ultraestável. Porém, tais características intrínsecas desses minerais seriam determinantes se tivessem sido detectadas grandes variações de diagênese entre os pontos estudados, o que parece não ter ocorrido.

No contexto geral da Bacia de Curitiba, são observadas duas tendências principais de paleocorrentes. Uma está relacionada às associações correlatas a borda Leste (A, B, C e D), e foram obtidas em estratificações cruzadas de unidades arenosas. Tais associações são intergradativas e, com exceção da Associação C, exibem rumo médio de paleocorrentes para Noroeste. A outra tendência corresponde a dados obtidos em fácies cascalhosas da Associação E, por meio da atitude dos clastos, e exibem rumos para Leste-Nordeste (Fig. 4).

CONCLUSÕES Os minerais pesados mais abundantes na Formação Guabirotuba são zircão e epídoto. Em primeiro lugar, o mineral predominante é o zircão, com frequência média de $67 \%$, embora possa alcançar localmente valores de quase $100 \%$. Em segundo, abundam-se os minerais do grupo do epídoto, particularmente o próprio 
epídoto, com frequência média de $18 \%$. Todavia, em alguns locais, esta frequência pode alcançar valores superiores a $50 \%$. Com base na distribuição destes minerais, foram definidas duas associações mineralógicas distintas: uma denominada de Alto Zircão (com quantidades relativas de zircão entre 51 e 97\%) e outra, Alto Epídoto (com quantidades relativas de epídoto entre 43 a 54\%).

Os rumos médios de paleocorrentes indicaram que as principais fontes de sedimentos para as associações de fácies A, B, C, D e F estão localizadas a Sudeste. Assim, provavelmente, o zircão teve como principais fontes as rochas da Província Graciosa e/ ou os metamorfitos do Complexo Atuba. O mineral epídoto é proveniente, principalmente, das rochas metamórficas do Complexo Atuba.

AGRADECIMENTOS Os resultados apresentados foram obtidos em âmbito de uma dissertação de Mestrado vinculada ao Departamento de Geologia da
Universidade Federal do Paraná (UFPR), ao qual expressamos nossos agradecimentos. Apresentamos nossos agradecimentos aos Laboratório de Estudos Sedimentológicos e Petrologia Sedimentar (LabESed), do Departamento de Geologia da UFPR (técnico Daniel Paredes), e ao Laboratório de Sedimentologia/ IGc da Universidade de São Paulo (USP), Professor Doutor Gianinni Fonseca. Ao Projeto POTE (Potencial de utilização de argilas da Bacia de Curitiba e região de CastroPiraí do Sul/ Convênio Araucária 042/protocolo 6337) pelo suporte financeiro, que permitiu a realização dos trabalhos de campo e laboratório, e à Coordenação de Aperfeiçoamento de Pessoal de Nível Superior (Capes), pela concessão da bolsa de Mestrado. Por fim, à colega Julia Lemos pela ajuda nas etapas iniciais de campo e discussões geológicas, aos professores doutores Gilson Burigo Guimarães e Mário Sérgio de Melo pelas discussões e sugestões em campo e à professora doutora Maria Cristina de Souza pelas sugestões, correções e auxílio na confecção do manuscrito.

\section{Referências}

Almeida F.F.M. 1952. Novas ocorrências de camadas supostas pliocênicas nos Estados de São Paulo e Paraná. Boletim da Sociedade Brasileira de Geologia, 1(1):53-58.

Becker R.M. 1982. Distribuição dos sedimentos cenozóicos na Região Metropolitana de Curitiba e sua relação com a estrutura geológica e morfológica regional. Tese de Doutorado, Universidade Federal do Rio Grande do Sul, Porto Alegre, 237 p.

Bigarella J.J. \& Salamuni R. 1962. Caracteres texturais dos sedimentos da Bacia de Curitiba. Boletim da Universidade do Paraná, 7:1-164.

Calliari L.J., Fischler C.T., Berquist C.R. 1990. Heavy mineral variability and provenance of the Virginia inner shelf and lower Chesapeake Bay, Virginia, EUA. Virginia Division of Mineral Resources, Publication 103, 124 p.

Cherniak D.J., Hanchar J.M., Watson E.B. 1997. Rare-earth diffusion in zircon. Chemical Geology, 143:289-301.

Coimbra A.M. 1976. Arenitos da Formação Bauru: estudo de áreas fonte. Dissertação de Mestrado, Instituto de Geociências, Universidade de São Paulo, São Paulo. 2 v.

Coimbra A.M., Sant'Ana L.G., Valarelli J.V. 1995. Bacia de Curitiba: estratigrafia e correlações regionais. In: SBG, Congresso Brasileiro de Geologia, 35, Salvador, Anais, p. 135-137.

Coutinho J. M.V., Coimbra A.M. 1974. O pré-cambriano no vale do rio Doce como fonte alimentadora de sedimentos costeiros. In: SBG, Congresso Brasileiro de Geologia, 28, Porto Alegre, Anais v.1, p. 43-56.

Cunha P.V.C. 2011. Caracterização e gênese de calcretes da Bacia de Curitiba, PR. Dissertação de Mestrado,
Universidade Federal do Paraná, Curitiba, 103 p.

Deer W.A., Howie R.A., Zussman J. 2000. Minerais Constituintes das Rochas. Uma introdução. 2. ed. Fundação Calouste Gulbenkian, 727 p.

Fiori A.P. \& Gaspar L.A. 1993. Considerações sobre a estratigrafia do Grupo Açungui (Proterozóico Superior), Paraná, Sul do Brasil. Boletim do Instituto de Geociências, São Paulo, Série Científica, v. 24, p. 1-19.

Galehouse J.S. 1971. Point Counting. In: Carver R.E. (ed) Procedures in Sedimentary Petrography. WileyInterscience, New York, p. 385-407.

Gualda G.A.R. \& Vlach S.R.F. 2005. The Serra da Graciosa A-type Granites and Syenites, southern Brazil. Part 1: Regional setting and geological characterization. Anais da Academia Brasileira de Ciências, 79(3):405-430.

Kaul P.F.T. 1984. Significado dos granitos anorogênicos da Suíte Intrusiva Serra do Mar na evolução da crosta do sul-sudeste do Brasil, no âmbito das folhas SG22, Curitiba e SG-23, Iguape. In: SBG, Congresso Brasileiro de Geologia, 33, Rio de Janeiro, RJ, Brasil, Anais..., 6:2815-2825.

Kaul P.F.T. \& Cordani U.G. 2000. Geochemistry of the Serra do Mar granitoid magmatism and tectonic implications, Southern Brazil. Revista Brasileira de Geociências, 30(1):15-119.

Krumbein W. C. \& Pettijohn F.J. 1938. Manual of sedimentary petrography. New York, D. AppletonCentury Co., 549 p.

Krumbein W.C. \& Sloss L.L. 1956. Stratigraphy and Sedimentation. W. H. and Freeman and Co., San Francisco, 660 p. 
Lima F.M. 2010. Faciologia e ambientes deposicionais da Formação Guabirotuba, Bacia de Curitiba, PR. Dissertação de Mestrado, Universidade Federal do Paraná, Curitiba, 103 p.

Machado D.A.M. 2009. Proveniência de sedimentos da Bacia de Curitiba por estudos de minerais pesados. Dissertação de Mestrado, Universidade Federal do Paraná, Curitiba, 54 p.

Mange M.A. \& Maurer H.F.W. 1992. Heavy Minerals in Colour. London, Chapman \& Hall, 147 p.

Melo M.S., Riccomini C., Hasui Y., Almeida F.F.M., Coimbra A.M. 1985. Geologia e evolução do sistema de Bacias Tafrogênicas continentais do sudeste do Brasil. Revista Brasileira de Geociências, 15(3):194-199.

Mezzadri G. \& Saccani E. 1989. Heavy mineral distribution in late quaternary sediment dispersal in sedimentary basins at active margins. Journal of Sedimentary Petrology, 59(3):412-422.

Miall A.D. 1985. Architectural-element analysis: a new method of facies analysis applied to fluvial deposits. Earth Science Reviews, 22:261-308.

Morton A.C., Hallsworth C.R. 1994. Processes controlling the composition of heavy mineral assemblages in sandstones. Sedimentary Geology, 124:3-30.
Riccomini C., Sant'Anna L.G., Ferrari A.L. 2004. Evolução Geológica do Rift Continental do Sudeste do Brasil. In: Mantesso Neto V., Bartorelli A., Carneiro C.D.R., BritoNeves B.B. (org.). Geologia do Continente Sul Americano: evolução da obra de Fernando Flávio Marques de Almeida. São Paulo, Beca Editora, p. 383-405.

Salamuni E., Salamuni R., Ebert H.D. 1999. Contribuição à Geologia da Bacia Sedimentar de Curitiba (PR). Boletim Paranaense de Geociências, 47:123-142.

Siga Jr. O., Basei M.A.S., Reis Neto J.M., Machiavelli A., Harara O.M. 1995. O Complexo Atuba: um cinturão Paleoproterozóico intensamente retrabalhado no Neoproterozóico. Boletim do Instituto de Geociências da Universidade de São Paulo, 26:69-98.

Tomazelli L.J. 1978. Minerais Pesados da Plataforma Continental do Rio Grande do Sul. Acta Geológica, 5(2):159.

Zalán P.V. \& Oliveira J.A.B. 2005. Origem e evolução estrutural do Sistema de Riftes Cenozóicos do Sudeste do Brasil. Boletim de Geociências da Petrobras, 13(2):269-300.

Manuscrito ID 20551

Recebido em: 17/01/2011

Aprovado em 23/04/2012 